\title{
Collodion Baby
}

\section{Gurubacharya SM${ }^{1}$, Subedi $K^{2}$, Aryal DR ${ }^{3}$}

${ }^{1}$ Dr. Simmi Mishra Gurbacharya, Registrar. ${ }^{2}$ Dr. Kalpana Subedi, Consultant. ${ }^{3}$ Dr. Dhan Raj Aryal, Consultant. NICU, Maternity Hospital, Thapathali, Kathmandu, Nepal.

Address for Correspondence: Dr. Simmi Mishra Gurubacharya. E-mail: sm_pul@rediffmail.com

A full-term SGA baby was born as a first twin to consanguinous parents with parchment-like membrane over the whole body, ectropion, eclabium, flat nose, and ear and restricted joint movements. The membrane started breaking on the second day of life in different parts of the body along with oozing of the blood. The diagnosis of Collodion Baby was made (Figure $1 \& 2$ ). The other twin born was normal.

Fig.1: Showing a Neonate with Collodion Membrane.

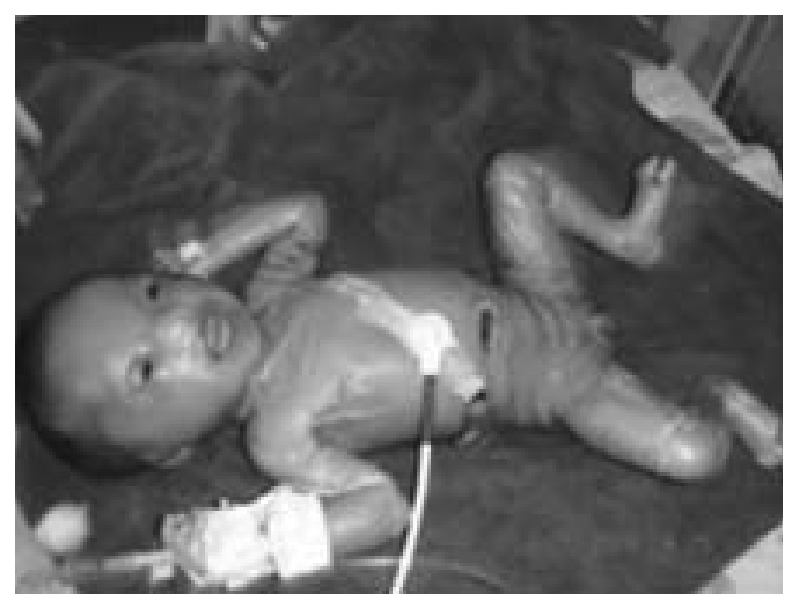

Fig.2: Showing a Neonate with Ectropion and Eclabium.

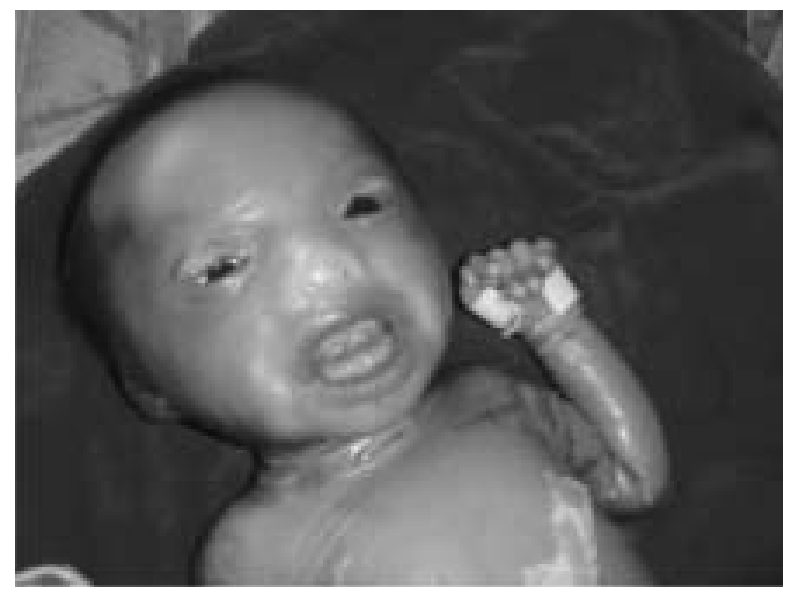

Infants born with a thick "saran- wrap" covering of skin (Collodion membrane) are referred to as Collodion babies. It is a rare congenital disorder with incidence of 1 in 300,000 live births ${ }^{1}$. Collodion baby is usually a manifestation of congenital ichthyosiform erythroderma or lamellar ichthyosis ${ }^{2}$. It may be a manifestation of various other conditions like trichothiodystrophy, Sjogren-Larsson syndrome, Conradi-Hunerman syndrome, Gaucher's diasease (Type IIB) and Refsum disease $^{3}$. The membrane in the early neonatal period can cause respiratory distress, painful cracks and fissures, temperature and fluid instability. The membrane sheds over a period of 2 to 4 weeks. Supportive treatment like humidified environment, application of emollients, intravenous fluids and prophylactic antibiotics is frequently required to prevent mortality.

\section{References}

1. Shwayder T, Ott F. All about ichthyosis. Paediat Clin N Am 1991; 835-857.

2. Darmstadt GL, Sidbury R. The Skin. In: Nelson Textbook of Pediatrics, $17^{\text {th }}$ edn. Eds. Behrman RE, Kliegman RM, Jenson HB. Saunders, 2004; pp 2201.

3. Dinulos Jamus G.H, Darmstadt GL. Dermatologic Conditions. In: Avery's Neonatology Pathophysiology \& Management of the newborn, $6^{\text {th }}$ edn. Eds MacDonald MG, Seshia Mary M.K, Mullett MD. Lippincott Williams \& Wilkins, 2005; pp 1489. 